\title{
Correlation Between Clinical And Magnetic Resonance Imaging Findings In Patients With Lumbosacral Radiculopathy
}

\author{
Mukul Kumar Sarkar ${ }^{1}$, Pijush Kumar Kundu ${ }^{2}$, Md. Munzur Alahi ${ }^{2}$, \\ Md Pervez Amin ${ }^{2}$, Achinta Kumar Mallick ${ }^{3}$, Quamruddin Ahmed ${ }^{4}$, Md. Kafiluddin ${ }^{5}$
}

\begin{abstract}
Low back pain accounts for a large amount of loss of productivity in the workforce. When the low back pain extends into the lower limb along the distribution of a dermatome then radiculopathy is said to be present. Although most people experience back pain during their lifetime, only a fraction experience lumbosacral radiculopathy as a consequence of nerve root compression or irritation. Almost $5 \%$ males and $2.5 \%$ females experience lumbosacral radiculopathy at some time in their lifetime. Magnetic resonance imaging (MRI) is the preferred investigation for the diagnosis of lumbosacral radiculopathy. So, in the evaluation of a patient of lumbosacral radiculopathy is essential to correlate clinical symptoms and signs with the finding detected in the MRI to arrive at a correct diagnosis and arrange an appropriate management.
\end{abstract}

So this study was done to see the correlation between clinical and MRI finding of radiculopathy at different nerve root level in patients with lumbosacral radiculopathy.

It was a cross sectional descriptive study. All $\mathbf{4 0}$ patients of lumbosacral radiculopathy who were presented to Rajshahi Medical College Hospital during the study period from 01/11/2011 to 30/10/2012 were included in the study.

There were 30 males and 10 females having an M: F ratio of 3:1. Mean age of total patients $43 \pm$ 14.74 years. $67.5 \%$ patients were between 20 to 50 years and $60 \%$ patients were performing heavy work. $67.5 \%$ patients had unilateral involvement while $32.6 \%$ patients had bilateral involvement. $72.5 \%$ patients had muscle weakness and $27.5 \%$ had no muscle weakness. $67.5 \%$ patients had sensory impairment and $32.5 \%$ had no sensory involvement. Knee jerk changes were present in $60 \%$ patients and ankle jerk changes in $66.66 \%$ patients. As expected $52.18 \%$ had L5 and $32.61 \%$ had S1 radiculopathy. The difference in clinical and MRI detection of root involvement was statistically significant $(p$ value $<0.05)$ in both sides at L4, L5 and S1 root levels but there was no significant difference at the L3 root level (p value 1.00) Intervertebral disc herniation was the commonest cause of lumbosacral radiculopathy $(72.32 \%)$ and second common cause was spinal canal stenosis (19.44\%). Others are intervertebral disc budging (61.52\%), disc protrusion (23.08\%) and disc extrusion (15.38\%).

Correlation between clinical severity and MRI grading of lumbosacral radiculopathy which was statistically significant. So, it is concluded that clinical findings correlate well with MRI finding, but all MRI abnormalities need not have a clinical significance.

${ }^{1}$ Assistant Professor, Department of neurology, Pabna Medical College, Pabna.

${ }_{2}^{2}$ Assistant Professor, Department of neurology, Rajshahi Medical College, Rajshahi.

${ }^{3}$ Registrar, Department of neurology, Rajshahi Medical College Hospital, Rajshahi.

${ }_{4}^{4}$ Professor, Department of neurology, Holy Family Red Crescent Medical College, Dhaka.

${ }^{5}$ Associate Professor and head, Department of neurology, Rajshahi Medical College, Rajshahi. 


\section{Introduction}

Low back pain accounts for a large amount of loss of productivity in the workforce. When the low back pain extends into the lower limb along the distribution of a dermatome then radiculopathy is said to be present. Although most people experience back pain during their lifetime, only a fraction experience lumbosacral radiculopathy as a consequence of nerve root compression or irritation ${ }^{1}$.

Almost 5\% males and 2.5\% females experience lumbosacral radiculopathy at some time in their lifetime ${ }^{2}$.The most frequent cause of lumbosacral radiculopathy is nerve root compression by a herniated disc. Root compression can also be caused by surrounding structures e.g. degenerative stenosis of root canal or spinal canal, spondylolisthesis or other less frequent pathological conditions like malignancies, infections or chemical irritation ${ }^{3}$.

Most lumbar disc herniations are preceded by bouts of varying degrees and duration of back pain. In many cases, an inciting event cannot be identified.

Pain eventually may radiate into the leg. Pain may be characterized as a shooting or stabbing pain. The distribution of the leg pain is somewhat dependent on the level of nerve root irritation. Higher herniations (third or fourth lumber levels) can radiate into the groin or anterior thigh. First sacral radiculopathy causes pain in the calf and bottom of the foot ${ }^{1}$. Fifth lumbar radiculopathy, which occurs most commonly, causes lateral and anterior thigh and leg pain. Often accompanying numbness or tingling occurs with a distribution similar to the pain. On examination, patients may be neurologically normal or show features of radiculopathy. A positive straight leg raising sign indicates that prolapsed lumbar disc is present. However, a crossed straight leg raising sign may be even more predictive of a lumbar disc disease. The back may appear scoliotic. Gait is often abnormal. Muscles weakness may be revealed particularly when testing is done by walking on heels and toes ${ }^{4}$.

To evaluate the lumbar sacral region, MRI is the investigation of choice. However, MRI alone is not enough to retrieve the cause of lumbosacral radiculopathy. Comparing clinical symptoms and signs with MRI findings at different nerve root level in patients with lumbosacral radiculopathy remains essential to determine which of the MRI detected abnormalities are symptomatic and thus to determine whether patients are eligible for surgical intervention ${ }^{5}$.

\section{Objectives}

To correlate between clinical and MRI findings of radiculopathy at different nerve root level in patients with lumbosacral radiculopathy.

\section{Material and Methods}

It was a cross sectional descriptive study. 40 patients of lumbosacral radiculopathy who were admitted into Neuromedicine, Neurosurgery and Medicine units of Rajshahi Medical College Hospital during the study period from $1^{\text {st }}$ November 2011 to $30^{\text {th }}$ October 2012 were included in the study.

Each study participant selected on the basis of predetermined inclusion and exclusion criteria.

Case definition of lumbosacral radiculopathy:

1. History of dominant complain of radicular pain rather than low back pain.

2. Any changes in sensation, muscle power and reflex changes in the lower limb. 
Lumbosacral radiculopathy may be in the form of involvement of lumbosacral nerve roots which present with following clinical features: ${ }^{6}$

\begin{tabular}{|c|c|c|c|c|}
\hline $\begin{array}{c}\text { Root } \\
\text { involvement }\end{array}$ & Pain location & Muscle weakness & $\begin{array}{c}\text { Sensory } \\
\text { distribution }\end{array}$ & $\begin{array}{c}\text { Reflex } \\
\text { change - } \\
\text { diminished / } \\
\text { absent }\end{array}$ \\
\hline L3 & Anterior thigh, groin & $\begin{array}{l}\text { Illiopsoas, hip } \\
\text { adductors and knee } \\
\text { extensors }\end{array}$ & $\begin{array}{l}\text { Lower medial } \\
\text { thigh }\end{array}$ & Knee jerk \\
\hline L4 & $\begin{array}{l}\text { Antero-lateral thigh and } \\
\text { medial part of leg }\end{array}$ & $\begin{array}{l}\text { Hip adductors and knee } \\
\text { extensors }\end{array}$ & $\begin{array}{l}\text { Medial part of } \\
\text { lower leg }\end{array}$ & Knee jerk \\
\hline L5 & $\begin{array}{l}\text { Postero-lateral thigh and } \\
\text { leg extending into } \\
\text { dorsum of foot and great } \\
\text { toe. }\end{array}$ & $\begin{array}{l}\text { Ankle dorsiflexors and } \\
\text { hip abductors }\end{array}$ & $\begin{array}{l}\text { Anterior lateral } \\
\text { lower leg, dorsum } \\
\text { of foot and great } \\
\text { toe. }\end{array}$ & None \\
\hline S1 & $\begin{array}{l}\text { Postero-lateral thigh and } \\
\text { Postero-lateral leg } \\
\text { extending into lateral } \\
\text { toes and heel. }\end{array}$ & $\begin{array}{l}\text { Ankle and plantar } \\
\text { flexors and hip } \\
\text { extensors. }\end{array}$ & $\begin{array}{l}\text { Lateral foot, } 4^{\text {th }} \\
\text { and } 5^{\text {th }} \text { toe and } \\
\text { sole of foot. }\end{array}$ & Ankle jerk \\
\hline
\end{tabular}

Association between variables were conducted applying Chi -square test. Correlation was taken statistically significant at the level $<0.05$.

\section{Results:}

Table 1: Frequency distribution of patient by age and sex. $(n=40)$

\begin{tabular}{|l|c|c|c|c|c|c|}
\hline \multirow{2}{*}{$\begin{array}{l}\text { Age groups } \\
(Y r s .)\end{array}$} & \multicolumn{4}{|c|}{ Sex } & \multicolumn{2}{c|}{ Total } \\
\cline { 2 - 7 } & \multicolumn{2}{|c|}{ Male } & \multicolumn{2}{c|}{ Female } & \multicolumn{2}{c|}{} \\
\cline { 2 - 7 } & $\mathrm{N}$ & $\%$ & $\mathrm{~N}$ & $\%$ & $\mathrm{~N}$ & $\%$ \\
\hline$<20$ & 1 & 50.0 & 1 & 50.0 & 2 & 5.0 \\
\hline $21-30$ & 5 & 55.6 & 4 & 44.4 & 9 & 22.5 \\
\hline $31-40$ & 6 & 75.0 & 2 & 25.0 & 8 & 20.0 \\
\hline $41-50$ & 8 & 80.0 & 2 & 20.0 & 10 & 25.0 \\
\hline $51-60$ & 6 & 85.7 & 1 & 14.3 & 7 & 17.5 \\
\hline$>60$ & 4 & 13.3 & 0 & 00 & 4 & 10.0 \\
\hline Total & 30 & 75.0 & 10 & 25.0 & 40 & 100.0 \\
\hline Mean \pm SD & $45.97 \pm 14.740$ & \multicolumn{2}{c|}{$34.10 \pm 11.16$} & \multicolumn{2}{c|}{$43.00 \pm 14.74$} \\
\hline
\end{tabular}

Table 1 shows the age and sex distribution of the patients. The mean age of the patients was $43.00 \pm 14.74$ years ranging from 18-65 years. The mean age of the male patients was $45.97 \pm 14.740$ years and female patients was $34.10 \pm 11.16$ years. Maximum number of the patients was in age group $41-50$ years. Male to female ratio of patients were 3:1. 
Table 2: Distribution of pain location by side of the patients $(n=40)$

\begin{tabular}{|l|c|c|}
\hline Pain location by side & Number & Percentage \\
\hline Left & 16 & 40.0 \\
\hline Right & 11 & 27.5 \\
\hline Both & 13 & 32.5 \\
\hline Total & 40 & 100.0 \\
\hline
\end{tabular}

Table 2 showed that distribution of pain in 16 (40.0\%) was on left side, 11 (27.5\%) on right side and 13 (32.5\%) on both side.

Table 3: Clinical Involvement of the nerve roots $(n=40)$.

\begin{tabular}{|c|c|c|}
\hline Nerve root involved & No of root involvement & $\%$ \\
\hline L3 & 3 & 6.52 \\
\hline L4 & 4 & 8.69 \\
\hline L5 & 24 & 52.18 \\
\hline S1 & 15 & 32.61 \\
\hline Total & 46 & 100.00 \\
\hline
\end{tabular}

NB: Number of root involvement is more as some patients had bilateral and multiple root involvement. Clinical examination revealed that L5 was the commonest root involvement $(52.18 \%)$ and $2^{\text {nd }}$ common root involvement S1 (32.61\%).

Table 4: Frequency and percentage distribution of patients by muscle weakness $(n=40)$.

\begin{tabular}{|l|l|l|}
\hline Muscle weakness & Number of patients & Percentage \\
\hline Present & 29 & $72.5 \%$ \\
\hline Absent & 11 & $27.5 \%$ \\
\hline
\end{tabular}

Table 4shows that clinical examination of the patients indicated that 29 (72.5\%) had muscle weakness and 11 (27.5\%) had no muscle weakness.

Table 5: Distribution of sensory function $(n=40)$

\begin{tabular}{|l|l|l|}
\hline Sensory function & Number of patients & Percentage \\
\hline Impaired & 27 & $67.5 \%$ \\
\hline Intact & 13 & $32.5 \%$ \\
\hline
\end{tabular}

Clinical examination of the patients indicated that sensory function impaired 27 (67.5\%) and sensory function intact 13 (32.5\%) patients.

Table 6: Frequency distribution of reflex changes of the patients $(n=40)$

\begin{tabular}{|l|c|c|c|c|}
\hline \multirow{2}{*}{ Reflex } & \multicolumn{2}{|c|}{ Diminished/Absent } & \multicolumn{2}{c|}{ Normal } \\
\cline { 2 - 5 } & Number & \% & Number & \% \\
\hline Knee jerk & 3 & 60.00 & 2 & 40.00 \\
\hline Ankle jerk & 10 & 66.66 & 5 & 33.33 \\
\hline
\end{tabular}

N.B.: L3, L4 nerve root reflect knee jerk and S1 nerve root reflects ankle jerk but L5 nerve root does not reflect any jerk.

Clinical examination of the patient revealed that knee jerk diminished or absent in $3(60.0 \%)$ and normal in 2 (40.0\%); ankle jerk diminished or absent in 10 (66.66\%) and normal in 5 (33.33\%). 
Table 7: Correlation between clinical and MRI findings of lumbosacral radiculopathy at different nerve root level $(n=40)$.

\begin{tabular}{|c|c|c|c|c|c|c|c|c|}
\hline \multirow{2}{*}{$\begin{array}{l}\text { Nerve } \\
\text { root } \\
\text { involve } \\
\text { ment }\end{array}$} & \multicolumn{2}{|c|}{$\begin{array}{c}\text { Clinical } \\
\text { lumbosacral } \\
\text { radiculopathy }\end{array}$} & \multicolumn{2}{|c|}{$\begin{array}{l}\text { MRI findings of } \\
\text { lumbosacral } \\
\text { radiculopathy }\end{array}$} & \multirow[t]{2}{*}{$\begin{array}{l}\text { Pearson } \\
\chi 2 \text { value }\end{array}$} & \multirow[t]{2}{*}{ df } & \multirow[t]{2}{*}{$\begin{array}{l}\text { P-value 2- } \\
\text { sided }\end{array}$} & \multirow[t]{2}{*}{ Interference } \\
\hline & $\mathbf{N}$ & $\%$ & $\mathbf{N}$ & $\%$ & & & & \\
\hline Rt.L ${ }_{3}$ & 1 & 2.80 & 2 & 5.60 & 0.061 & 1 & 1.00 & $\begin{array}{l}\text { Statistically not } \\
\text { significant }\end{array}$ \\
\hline Lt.L ${ }_{3}$ & 1 & 2.80 & 2 & 5.60 & 0.061 & 1 & 1.00 & $\begin{array}{l}\text { Statistically not } \\
\text { significant }\end{array}$ \\
\hline Rt.L ${ }_{4}$ & 4 & 11.10 & 6 & 16.70 & 11.025 & 1 & 0.01 & $\begin{array}{l}\text { Statistically highly } \\
\text { significant }\end{array}$ \\
\hline Lt.L ${ }_{4}$ & 2 & 5.60 & 7 & 19.10 & 8.773 & 1 & 0.033 & $\begin{array}{l}\text { Statistically } \\
\text { significant }\end{array}$ \\
\hline Rt.L ${ }_{5}$ & 13 & 36.10 & 19 & 52.80 & 8.276 & 1 & 0.006 & $\begin{array}{l}\text { Statistically highly } \\
\text { significant }\end{array}$ \\
\hline Lt.L ${ }_{5}$ & 19 & 52.80 & 22 & 61.10 & 9.034 & 1 & 0.005 & $\begin{array}{l}\text { Statistically highly } \\
\text { significant }\end{array}$ \\
\hline Rt.S $\mathbf{S}_{1}$ & 8 & 22.20 & 9 & 25.00 & 21.429 & 1 & 0.000 & $\begin{array}{l}\text { Statistically highly } \\
\text { significant }\end{array}$ \\
\hline Lt.S ${ }_{1}$ & 7 & 19.40 & 8 & 22.20 & 6.13 & 1 & 0.030 & $\begin{array}{l}\text { Statistically } \\
\text { significant }\end{array}$ \\
\hline Total & 55 & 152.8 & 75 & 208.1 & & & & \\
\hline
\end{tabular}

N.B: Total number of patients 40 but MRI findings found 36 patients.

P-value was statistically significant at the level of 0.05 .

Table 7 showing correlation between clinically and MRI findings of lumbosacral radiculopathy at different nerve root levels. Statistically significant difference was detected in L4, L5, and S1 nerve roots on both sides, but L3 root involvement was not statistically significant on both sides.

Table 8: frequency distribution of causes of lumbosacral radiculopathy detected by MRI (n=40)

\begin{tabular}{|l|l|l|}
\hline Causes of lumbosacral radiculopathy & $\mathrm{N}$ & $\%$ \\
\hline Intervertebral disc herniation & 26 & $72.22 \%$ \\
\hline Spinal canal stenosis & 7 & $19.44 \%$ \\
\hline Spondylolisthesis & 2 & $5.56 \%$ \\
\hline Benign neoplasm (Ependymoma) & 1 & $2.78 \%$ \\
\hline Total & 36 & $100.00 \%$ \\
\hline
\end{tabular}

Table 8 showing intervertebral disc herniation was the commonest cause of lumbosacral radiculopathy (72.22\%) and $2^{\text {nd }}$ common cause spinal canal stenosis (19.44\%)

Table 9: MRI grading of intervertebral disc herniation $(n=40)$

\begin{tabular}{|l|l|l|}
\hline MRI grading intervertebral disc herniation & $\mathrm{N}$ & $\%$ \\
\hline Bulge & 16 & $61.54 \%$ \\
\hline Protrusion & 6 & $23.08 \%$ \\
\hline Extrusion & 4 & $15.38 \%$ \\
\hline Tear & 0 & $00 \%$ \\
\hline Total & 26 & $100 . \%$ \\
\hline
\end{tabular}


Table 9 showing intervertebral disc bulge 16 (61.54\%), disc protrusion 6 (23.08\%) and disc extrusion 4 (15.38\%) patients.

Table 10: Correlation between clinical severity and MRI grading of lumbosacral radiculopathy $(\mathbf{n}=\mathbf{4 0})$

\begin{tabular}{|l|l|l|l|l|}
\hline \multirow{2}{*}{$\begin{array}{l}\text { Clinical severity } \\
\text { of lumbosacral } \\
\text { radiculopathy }\end{array}$} & MRI grading of lumbosacral radiculopathy & Total \\
\cline { 2 - 4 } & Mild & Moderate & Severe & \\
\hline Mild & $9(22.5 \%)$ & $1(2.5 \%)$ & $2(5.0 \%)$ & $12(30.0 \%)$ \\
\hline Moderate & $7(17.5 \%)$ & $9(22.5 \%)$ & $1(2.5 \%)$ & $17(42.5 \%)$ \\
\hline Severe & $5(12.5 \%)$ & $3(7.5 \%)$ & $3(7.5 \%)$ & $11(27.5 \%)$ \\
\hline Total & $21(52.5 \%)$ & $13(32.5 \%)$ & $6(15.0 \%)$ & $40(100.0 \%)$ \\
\hline
\end{tabular}

Table 10 showing that MRI grading at lumbosacral radiculopathy mild 21 (52.5\%), moderate 13 (32.5\%) and severe 6 (15.0\%) patients. Correlation between clinical severity and MRI grading of lumbosacral radiculopathy which was statistically not significant, p value was 0.085 .

\section{Discussion:}

The present study was carried out in Rajshahi Medical College Hospital, Rajshahi. A total number of 40 patients were included in this study. This study is therefore not a community based study and does not exactly reflect the demographic pattern of lumbosacral radiculopathy.

Back pain resulting from lumbosacral radiculopathy is one of the most common cause of disability in working age adults. Between $60-80 \%$ of adults suffer from low back pain of sometime in their lives. MRI has become a modality of choice in evaluation of lumbosacral radiculopathy ${ }^{7}$.

So this study was done to find out the correlation between lumbosacral radiculopathy patients presenting with low back pain radiating to the lower limbs below the knee and the findings of the MRI scan of the lumbosacral region.

Table 1 shows the demographic characteristics of the patients of this study. $75 \%$ of the patients were male, $67.5 \%$ of the patients were between the ages of 20 to 50 years, and $27.5 \%$ were above 50 years of age. In a similar study of 119 patients of prolapsed disc with sciatica syndrome conducted in India ${ }^{1}$, there were 57 males and 62 females, $67 \%(81 / 119)$ patients were between 20 to 50 years and 31\% (36/119) patients were above 50 years.
Table 2 shows that $67.5 \%$ of the patients had unilateral pain while the $32.5 \%$ of the patients had bilateral pain. Posterolateral disc herniation is more common than central disc herniation. So unilateral involvement is more common than bilateral involvement.

Table 3 shows that clinical evaluation of our patients revealed that L5 involvement was commonest $(52.18 \%)$ and S1 was next common (32.61\%). In the study by Janardhana et al. (2010) also, L5 involvement was found to be commonest (80/119) and S1 involvement was next common (46/119) which matched with study.

Table 4 shows that $72.5 \%$ patients had muscle weakness and $27.5 \%$ patients had no muscle weakness. It is not consistent with other studies (28\% patients had muscle weakness)

Table 5 shows that sensory function was impaired in $27(67.5 \%)$ and sensory function was intact in 13 (32.5\%) patients.

Table 6 shows that 10 patients had involvement of the Ankle jerk and 3 patients had involvement of the knee jerk. This correlates well to the finding that $\mathrm{S} 1$ root is involved in $32.61 \%$ of patients and the L4 root is involved in $8.69 \%$ of the patients which are the roots supplying the knee jerk and ankle jerk, respectively. 
Table 7 shows that the frequency and percentage of patients clinically detected to have radiculopathy and those having radiculopathy in their MRI. At all the root levels from L3 to S1 MRI showed radiculopathy in more patients than radiculopathy as detected clinically. Clinically radiculopathy was detected in 55 (73.33\%) patients while MRI detected radiculopathy in 75 patients (there were total 40 patients but radiculopathy both clinically and by MRI was detected in more patients as some patients had involvement in more than one root).Janardhana et al. (2010) in their study also found that out of 169 levels of disc lesions in the MRI only 89 (52.66\%) were clinically symptomatic.At a $\mathrm{p}$ value of < 0.05 , correlation between clinical evaluation and MRI findings were statistically significant in the L4, L5 and S1 root levels in both side but not significant in the S3 root level on both side. Some studies have correlated clinical findings with MRI findings of lumbosacral radiculopathy at different anatomical level ${ }^{1,5,9,10,11}$.

Table 8 shows that causes of lumbosacral radiculopathy detected by MRI. This study shows that intervertebral disc herniation was the commonest cause of lumbosacral radiculopathy $(72.32 \%)$ and $2^{\text {nd }}$ common cause spinal canal stenosis $(19.44 \%)$ which is consistent with other studies.

Table 9 shows that MRI grading of intervertebral disc herniation revealed that intervertebral disc bulge 16 (61.52\%), disc protrusion 6 (23.08\%) and disc extrusion 4 (15.38\%) patients. In the study by Younis F et al. 2011 revealed that disc bulge 75\% and intervertebral disc herniation 25\%.

Table 10 showing that MRI grading at lumbosacral radiculopathy mild 21 (52.5\%), moderate 13 (32.5\%) and severe 6 (15.0\%) patients. Correlation between clinical severity and MRI grading of lumbosacral radiculopathy which was statistically not significant, $\mathrm{p}$ value was 0.085 . This kind of study by Younis $\mathrm{F}$ et $\mathrm{al}^{7} .2011$ revealed that $76 \%$ patients had MRI evidence of nerve root or thecal sac compression. $48 \%$ had mild to moderate compression while $28 \%$ had severe nerve compression ${ }^{7}$. Correlation between clinical severity and MRI grading of lumbosacral radiculopathy which was statistically significant ( $p$ value 0.006$)^{1}$. Janardhana 2010 also found that the degree of disc displacement in MRI did not correlate with any subjective symptoms, nor did nerve root enhancement or nerve root compression ${ }^{1}$.

Very few studies have correlated clinical findings with MRI findings in patients with low back pain radiating to the lower limb ${ }^{1,5,9,10 \text {, and } 11}$.Thefindings of this study correlate well to what has been reported in the literature.

\section{Conclusions:}

Clinical evaluation and MRI findings were statistically significant at the L4, L5 and S1 root levels on both side ( $p$ value $<0.005$ ) but L3 root level on both side was not significant ( $p$ value 1.00). Clinical severity and MRI grading of lumbosacral radiculopathy statistically not significant (p- value 0.085).

So, it is concluded that clinical findings correlate well with MRI findings but all MRI abnormalities need not have a clinical significance. In patients of low back pain with lumbosacral radiculopathy, management should not be based exclusively on findings as detected by MRI scan rather clinical finding should also be given due importance.

\section{References}

1. Janardhana AP, Rajagopal, Rao $S$, and Kamath A.2010. 'Correlation between clinical features and magnetic resonance imaging findings in lumbar disc prolapse'. Indian J Orthop; 44(3):263-269.

2. Sahrakar Kamran 2011. 'Lumbar Disc Disease'. Medscape; 1-3.

3. Suzan Coster AE, Sebastian F.T.M. de Bruijn AE, De'nass L.J. Tavy, et al. 2010. 'Diagnostic value of history, Physical examination and needle electromyography in diagnosing lumbosacral radiculopathy'. J Neurol; 257: 332-337.

4. van Rijn JC, Klemetso N, Reitsma JB, et al. 2006. 'Symptomatic and asymptomatic abnormalities in patients with lumbosacral radicular syndrome: Clinical examination compared with MRI'. Clinical Neurology and Neurosurgery; 108:553-557.

5. Beattie PF, Meyers SP, Stratford P, et al. 2000. 'Associations between patient report of symptoms and anatomic impairment visible on lumbar 
magnetic resonance imaging'. Spine; 25(7):819828.

6. Geckle DS, HLavin ML. 1995. Spondylosis and disc disease. In Sanuels MA, Feske S, eds. Office practice of neurology: Newyork: Churchill Livingstone.

7. Younis F, Shahzad and Rasool F. correlation of Magnetic Resonance patterns of lumber disc disease with clinical symptomatology of patients. Annals 2011; 17 (1): 41-47

8. Greenberg MS. 2006. 'Low back pain and radiculopathy'. Handbook of Neurosurgery, 6th ed. Thieme Medical Publishers, New York; 289-301.
9. Milette PC. 2000. 'Classification, diagnostic imaging, and imaging characterization of a lumbar herniated disk. RadiolClin North Am; 38:1267-292.

10. Borenstein DG, O'Mara JW Jr, Boden SD, et al. 2001. 'The value of magnetic resonance imaging of the lumbar spine to predict low-back pain in asymptomatic subjects: a seven-year follow-up study'. J Bone Joint Surg Am; 83A:1306-11.

11. Rankine JJ, Fortune DG, Hutchinson CE, Hughes DG, Main CJ. 1998. 'Pain drawings in the assessment of nerve root compression: $A$ comparative study with lumbar spine magnetic resonance imaging'. Spine; 23:1668-676.

All corresponds to Dr. Mukul Kumar Sarkar Assistant Professor Department of neurology Pabna Medical College, Pabna. Email: mukul34rmch@gmail.com 